\title{
Research on High-Precision Form Grinding Technology of Gear Based on Ambient Temperature Adaptability
}

\author{
Xinrong Liu (i) and Zhonghou Wang (i) \\ School of Mechanical Engineering, University of Shanghai for Science and Technology, No. 516, Jungong Road, Yangpu, \\ Shanghai 200093, China
}

Correspondence should be addressed to Zhonghou Wang; wang_zhonghou18@163.com

Received 27 February 2018; Revised 7 May 2018; Accepted 27 May 2018; Published 15 July 2018

Academic Editor: Akhil Garg

Copyright (C) 2018 Xinrong Liu and Zhonghou Wang. This is an open access article distributed under the Creative Commons Attribution License, which permits unrestricted use, distribution, and reproduction in any medium, provided the original work is properly cited.

\begin{abstract}
The thermal error of high-precision computer numerical control (CNC) form grinding machine has become the critical factor affecting its locating precision. Because the thermal error is more complicated to be measured directly, most of the measurement tests are usually aimed at no-load conditions. In this article, a method to evaluate the machine tool thermal error based on the principle of tooth profile error through the gear grinding precision is presented. Based on high-precision CNC form grinding machine need to maintain isoperibol, this paper proposed the ambient temperature as a variable, for different ambient temperature to measure the thermal error of the machine tool. According to the measurement results of the thermal error, the method of partial least squares neural network is used to structure the thermal error prediction model of the machine tool. The experimental data show that the grade of the gear precision can reach four levels at different temperatures. This approach shows a promising prospect in the application of high-precision CNC gear form grinding machine in the future.
\end{abstract}

\section{Introduction}

New research shows that the thermal error of CNC accounts for 70 percent of total error. Moreover, there are many means to reduce the thermal error of the $\mathrm{CNC}$, for instance, to design the thermal symmetry structural of the machine tool and to separate the heat source from the main machine body. Nevertheless, it must result in much material cost and higher manufacture cost, due to change the structure design. Error compensation is an economical and effective compensation method [1-3].

The vibration and noise of the gear transmission system are one of the hotspots concerned by the researchers of the gear transmission system. Due to the competition in the automotive market and many countries' requests to the vehicle noise has been more and more strict. German Volkswagen put forward some requests accordingly on one tooth and three cross sections for gear form grinding process in 2007, as shown in Figure 1. There are few manufacturers of gear grinding machines that can satisfy some performance specification requirements. With the popularity of new energy vehicles, it is necessary to set higher requirements for the accuracy of gear manufacturing. It will lead to abnormal gear meshing, due to gear manufacturing error, installation error, and inadequate support system stiffness, gear modification becomes an important method to solve this problem. In order to obtain the best transmission performance, Wang et al. discussed the form grinding method orient gear meshing performance, while the high-performance gear manufacture cannot separate from the high-precision gear form grinding technology [4]. At the same time, in order to get highperformance gear, grinding wheel accuracy is very important. Ding et al. made further research in the related fields [5-9].

In order to obtain high-precision gear, universities and other institutions of scientific research institutions spare no effort in relate fields and achieved fruitful results $[10,11]$. The model of thermal error in NC machine tool is usually divided into empirical thermal error model and theoretical thermal error model. The empirical thermal error model is 
based on the mathematical model of the temperature rise of the sensitive point, the machine tool speed, and the feed rate, and the thermal drift is the output. The establishment of the theoretical thermal error model requires the three forms of heat transfer as the basis for calculation. After solving the temperature field of a certain part or machine of the machine tool, the corresponding displacement field is calculated. Because of the large space of factory, it will require tremendous amounts of energy, if the whole space keeps at a constant temperature. Therefore, it is necessary to improve the precision grinding technology to a new level through technological innovation.

In the thermal error compensation of machine tool, in order to improve the efficiency, some scholars consider that combining the measured error with the comprehensive model [12-17]. For example, Zhang et al. have presented a method of obtaining 21 error elements in space by 22 straight lines in 1988 [12] and Chen et al. on the base of the previous study that decrease from 22 lines to 15 lines [13]. Domestic researchers also proposed 14-line and 9-line measurement method. Efficiency has also increased with the line gradually reducing, but the actual measurement is more complicated and more time-consuming. The less measurement lines mean less workload of measurement but cannot fully reflect the overall thermal deformation of the measurement system, and sometimes through a variety of measurements, it may not be able to find the best measurement points. So it cannot be good for measuring the thermal error of machine tools to provide better measurement ideas.

At the present stage, in order to make it easier to measure the thermal error, usually use no-load way to preheat the machine to obtain the correlation data about thermal error. In the actual production process, the machine tool cannot always be in no-load condition. The no-load and normal condition belongs to two vastly different types of states. By the no-load condition, we arrive at some conclusions which are insufficient guiding significance to production practice. Based on the above shortcomings, according to the multiple of thermal errors, taking gear form grinding process for research background, based on the formation principle of spiral bevel gears surface errors, this manuscript studied the mechanism of thermal error compensation about the CNC machine tool under nonisothermal conditions. This paper presents a method to measure the CNC thermal error indirectly, and then through the modeling and prediction of related parameters, we get the method of the error compensation which can meet the actual processing requirements.

\section{Error Analysis Hypothesis}

In this paper, we take the high-precision NC forming grinding machine developed independently as study object and centers on its related problem. The machining region is shown in Figure 2. In order to grasp the principle contradictions about thermal error for NC machine tool, some assumptions are made as follows.

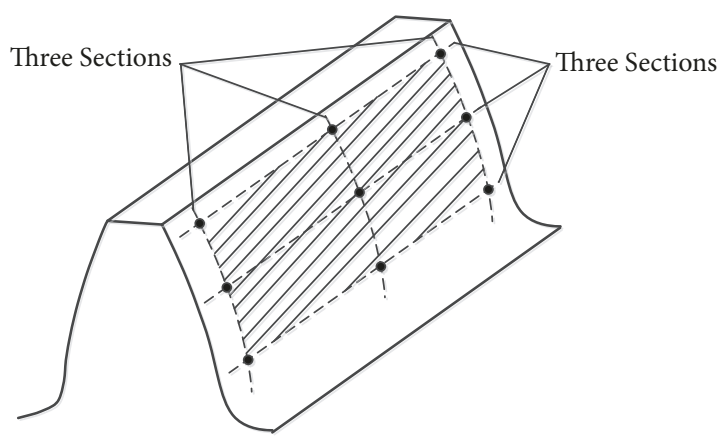

FIGURE 1: Diagrammatic sketch of the three sections of one tooth.

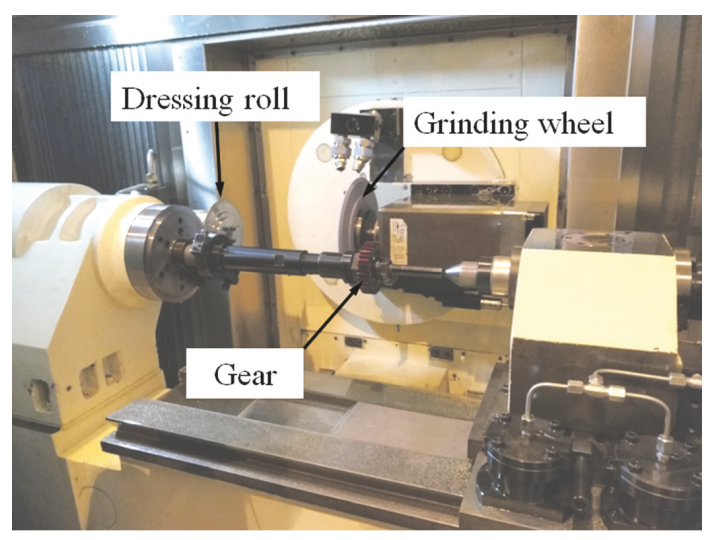

Figure 2: Machine tool structure.

First, due to the continuity of the production process, it will not study the compensation before the machine reaches thermal equilibrium.

Second, because the machine tool is in a steady state of operation, small machining allowance, and small mutual interaction between grinding wheel and gear, so we take no account of the dynamic change of grinding force and other factors.

Third, the wear of grinding wheel throughout the production process is not considered.

Fourth, the products produced by the factory in a period of time are relatively simple and the process is relatively fixed.

Fifth, the deformation of the parts of the machine tool has a single-directional.

Sixth, after dressing grinding wheel, the wheel profile has met the requirements.

\section{Error Analysis of Moving Parts in High-Precision Computer Numerical Control Form Grinding Machine}

3.1. The Error Analysis about the Slide Pair Kinematic Parameters. It will have the corresponding error when the highprecision computer numerical control forming grinding 


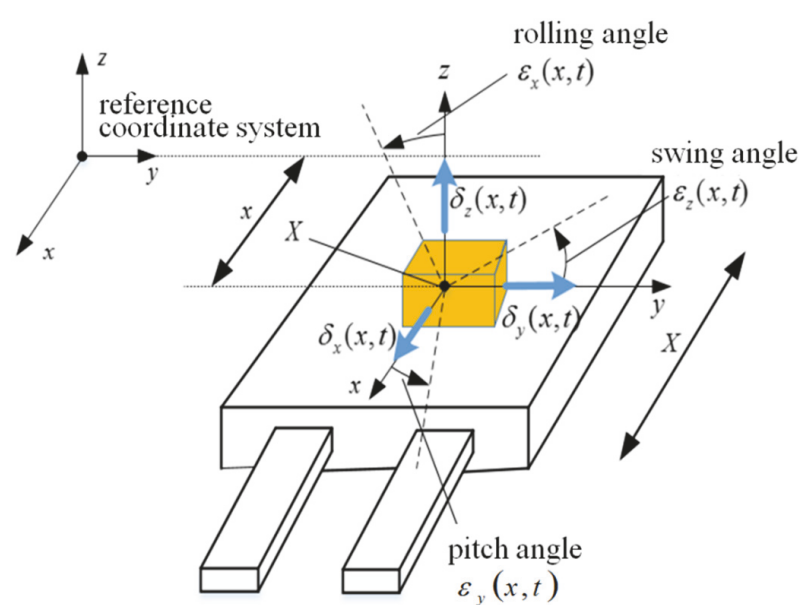

FIGURE 3: Six pairs of motion errors.

TABLE 1: The error of sliding pair.

\begin{tabular}{lcc}
\hline & Direction X & Direction Y \\
\hline Straightness error of the X direction & $\delta_{x}(x, t)$ & $\delta_{x}(y, t)$ \\
Straightness error of the Y direction & $\delta_{y}(x, t)$ & $\delta_{y}(y, t)$ \\
Straightness error of the Z direction & $\delta_{z}(x, t)$ & $\delta_{z}(y, t)$ \\
Rolling error around X direction & $\varepsilon_{x}(x, t)$ & $\varepsilon_{x}(y, t)$ \\
Rolling error around Y direction & $\varepsilon_{y}(x, t)$ & $\varepsilon_{y}(y, t)$ \\
Rolling error around Z direction & $\varepsilon_{z}(x, t)$ & $\varepsilon_{z}(y, t)$ \\
\hline
\end{tabular}

machine is working; the error can be divided into translation error and angular error [18].

If the part moves along the $\mathrm{X}$-coordinate axis, the six degree errors of the moving part are as follows: the straightness error of the $\mathrm{X}$ direction is $\delta_{x}(x, t)$, the straightness error of the $\mathrm{Y}$ direction is $\delta_{y}(x, t)$, the straightness error of the $\mathrm{Z}$ direction is $\delta_{z}(x, t)$, the rolling error around $\mathrm{X}$ direction is $\varepsilon_{x}(x, t)$, the rolling error around $\mathrm{Y}$ direction is $\varepsilon_{y}(x, t)$, and the rolling error around $\mathrm{Z}$ direction is $\varepsilon_{z}(x, t)$, as shown in Figure 3. There are 2 main prismatic pairs in the highprecision computer numerical control forming gear grinding machine. The major form of error is similar to this, so no longer elaborated. The error of $\mathrm{X}$ direction and $\mathrm{Y}$ direction is shown in Table 1 .

3.2. Analysis of Motion Error of Revolute Pair. Rotating parts of the high-precision computer numerical control forming grinding machine also have six degree errors. Assuming that the origin position and the coordinate axis of the motion coordinate system $\mathrm{A}$ and the relative reference coordinate system $\mathrm{R}$ are exactly the same before starting the motion, when the rotation angle around the A axis's $\mathrm{Z}$ direction is 6 degrees of freedom error, rotation angle error is $\varepsilon_{x}(\varphi, t)$, rotation angle error is $\varepsilon_{y}(\varphi, t)$, rotation angle error is $\varepsilon_{z}(\varphi, t)$, translation error is $\delta_{x}(\varphi, t)$, translation error is $\delta_{y}(\varphi, t)$, and translation error is $\delta_{z}(\varphi, t)$, as shown
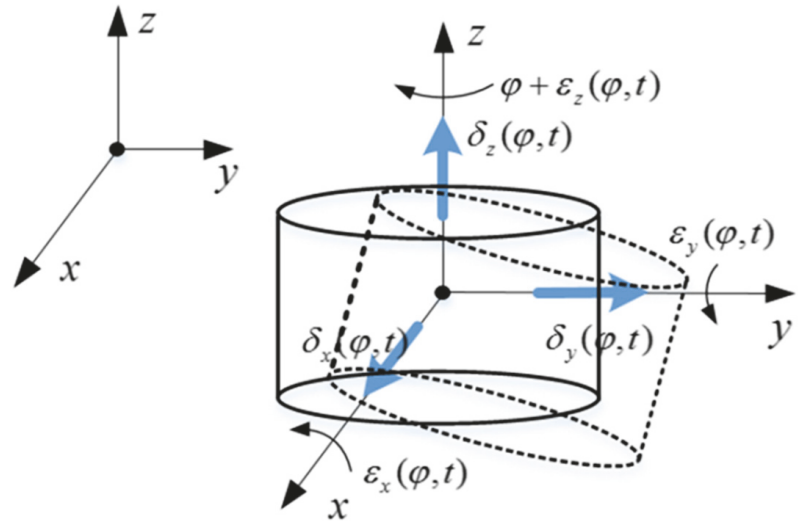

FIGURE 4: Six motion errors of revolute pairs.

in Figure 4. There are 2 main revolute pairs in the highprecision computer numerical control forming gear grinding machine.

3.3. Analysis of Vertical Error. In the movement process, besides the motion errors and revolute pair errors, the high accuracy computer numerical control forming gear grinding machine will produce perpendicularity error because the axes are not perpendicular to each other.

Because of the high-precision computer numerical control forming grinder only has two coordinate axes $\mathrm{X}$ and $\mathrm{Y}$, only one perpendicularity is produced during the movement, that is the perpendicularity error $S_{x y}$ between the shaft $\mathrm{X}$ and the shaft $\mathrm{Y}$. In this paper, it is converted into motion error or revolution error by projection method to be calculated.

\section{The Comprehensive Error Model of High- Precision Computer Numerical Control Gear Grinding Machine}

There are two transmission chains in the high-precision computer numerical control forming grinding machine: one is through the bed of machine tool to the gear, and the other one comes from the grinding machine to the grinding wheel. The interaction between the two transmission chains is established by the contact between the grinding wheel and the gear, and the relative position error between the wheel and the gear directly affects the accuracy of the machining. In this paper, the error synthesis model of a high-precision computer numerical control gear grinding machine is discussed by use of homogeneous coordinate transformation method. The thermal and geometric errors are compensated by this error synthesis model.

4.1. Homogeneous Coordinate Transformation. In the threedimensional coordinate, the calculation methods of homogeneous coordinate transformation are as follows, which is shown in Figure 5. Hypothetical space has a coordinate system $O_{A} X_{A} Y_{A} Z_{A}$, the coordinates of a point $P$ 


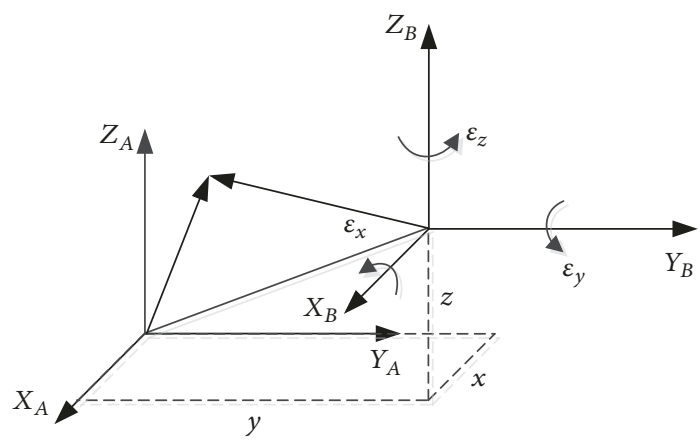

FIGURE 5: The diagram of homogeneous coordinate transformation.

in the coordinate system are $O_{A} X_{A} Y_{A} Z_{A}$, when coordinate system $O_{A} X_{A} Y_{A} Z_{A}$ moves $x$ along the $X_{A}$ axis to get a new coordinate system $O_{B} X_{B} Y_{B} Z_{B}$, the relationship between the coordinates of point $P$ in the new coordinate system $\left(x_{B}, y_{B}, z_{B}\right)$ and the coordinates in the original coordinate system $\left(x_{A}, y_{A}, z_{A}\right)$ can be expressed as follows:

Three-dimensional translation homogeneous coordinate transformation matrix of $\operatorname{Trans}(x)$ expressed among $X_{A}$ axis to translate $x$ is

$$
\begin{aligned}
{\left[\begin{array}{c}
x_{A} \\
y_{A} \\
z_{A} \\
1
\end{array}\right] } & =\left[\begin{array}{llll}
1 & 0 & 0 & x \\
0 & 1 & 0 & 0 \\
0 & 0 & 1 & 0 \\
0 & 0 & 0 & 1
\end{array}\right]\left[\begin{array}{c}
x_{B} \\
y_{B} \\
z_{B} \\
1
\end{array}\right]=\operatorname{Trans}(x)\left[\begin{array}{c}
x_{B} \\
y_{B} \\
z_{B} \\
1
\end{array}\right] \\
\operatorname{Trans}(x) & =\left[\begin{array}{llll}
1 & 0 & 0 & x \\
0 & 1 & 0 & 0 \\
0 & 0 & 1 & 0 \\
0 & 0 & 0 & 1
\end{array}\right]
\end{aligned}
$$

Similarly, the three-dimensional homogeneous coordinate transformation matrix that translates $y$ along $Y_{A}$ axis and $z$ along $Z_{A}$ axis, respectively, is

$$
\begin{aligned}
& \operatorname{Trans}(y)=\left[\begin{array}{llll}
1 & 0 & 0 & 0 \\
0 & 1 & 0 & y \\
0 & 0 & 1 & 0 \\
0 & 0 & 0 & 1
\end{array}\right] \\
& \operatorname{Trans}(z)=\left[\begin{array}{llll}
1 & 0 & 0 & 0 \\
0 & 1 & 0 & 0 \\
0 & 0 & 1 & z \\
0 & 0 & 0 & 1
\end{array}\right]
\end{aligned}
$$

When the coordinate system $O_{A} X_{A} Y_{A} Z_{A}$ is rotated around the $X_{A}$ axis $\varepsilon_{x}$ to obtain a new coordinate system $O_{B} X_{B} Y_{B} Z_{B}$, the relationship between the coordinates of the point $P$ in the new coordinate system $\left(x_{B}, y_{B}, z_{B}\right)$ and the coordinates in the original coordinate system $\left(x_{A}, y_{A}, z_{A}\right)$ can be expressed as

$$
\begin{aligned}
{\left[\begin{array}{c}
x_{A} \\
y_{A} \\
z_{A} \\
1
\end{array}\right] } & =\left[\begin{array}{cccc}
1 & 0 & 0 & 0 \\
0 & \cos \varepsilon_{x} & -\sin \varepsilon_{x} & 0 \\
0 & \sin \varepsilon_{x} & \cos \varepsilon_{x} & 0 \\
0 & 0 & 0 & 1
\end{array}\right]\left[\begin{array}{c}
x_{B} \\
y_{B} \\
z_{B} \\
1
\end{array}\right] \\
& =\operatorname{Rot}\left(\varepsilon_{x}\right)\left[\begin{array}{c}
x_{B} \\
y_{B} \\
z_{B} \\
1
\end{array}\right]
\end{aligned}
$$

where $\operatorname{Rot}\left(\varepsilon_{x}\right)$ represents a three-dimensional homogeneous coordinate transformation matrix rotated $\varepsilon_{x}$ about the $X_{A}$ axis:

$$
\operatorname{Rot}\left(\varepsilon_{x}\right)=\left[\begin{array}{cccc}
1 & 0 & 0 & 0 \\
0 & \cos \varepsilon_{x} & -\sin \varepsilon_{x} & 0 \\
0 & \sin \varepsilon_{x} & \cos \varepsilon_{x} & 0 \\
0 & 0 & 0 & 1
\end{array}\right]
$$

Similarly, three-dimensional homogeneous coordinate transformation matrix around the $Y_{A}$ axis rotation $\varepsilon_{y}$ and $Z_{A}$ axis rotation $\varepsilon_{z}$, respectively, is

$$
\begin{aligned}
\operatorname{Rot}\left(\varepsilon_{y}\right) & =\left[\begin{array}{cccc}
\cos \varepsilon_{y} & 0 & \sin \varepsilon_{y} & 0 \\
0 & 1 & 0 & 0 \\
-\sin \varepsilon_{y} & 0 & \cos \varepsilon_{y} & 0 \\
0 & 0 & 0 & 1
\end{array}\right] \\
\operatorname{Rot}\left(\varepsilon_{z}\right) & =\left[\begin{array}{ccccc}
\cos \varepsilon_{z} & -\sin \varepsilon_{z} & 0 & 0 \\
\sin \varepsilon_{z} & \cos \varepsilon_{z} & 0 & 0 \\
0 & 0 & 1 & 0 \\
0 & 0 & 0 & 1
\end{array}\right]
\end{aligned}
$$

When the coordinate system $O_{A} X_{A} Y_{A} Z_{A}$, respectively, transforms $x, y, z$ along the $X_{A}, Y_{A}, Z_{A}$ axis and then revolves $\varepsilon_{x}, \varepsilon_{y}, \varepsilon_{z}$, respectively, around $X_{A}, Y_{A}, Z_{A}$ to obtain a new coordinate system $O_{B} X_{B} Y_{B} Z_{B}$, then the three-dimensional homogeneous coordinate transformation matrix of coordinate system $O_{A} X_{A} Y_{A} Z_{A}$ to the coordinate system $O_{B} X_{B} Y_{B} Z_{B}$ is

$$
\begin{aligned}
{ }_{B}^{A} T= & \operatorname{Trans}(x) \times \operatorname{Trans}(y) \times \operatorname{Trans}(z) \times \operatorname{Rot}\left(\varepsilon_{x}\right) \\
& \times \operatorname{Rot}\left(\varepsilon_{y}\right) \times \operatorname{Rot}\left(\varepsilon_{z}\right)
\end{aligned}
$$

Take (2), (3), (4), (6), (7), and (8) into (9): 


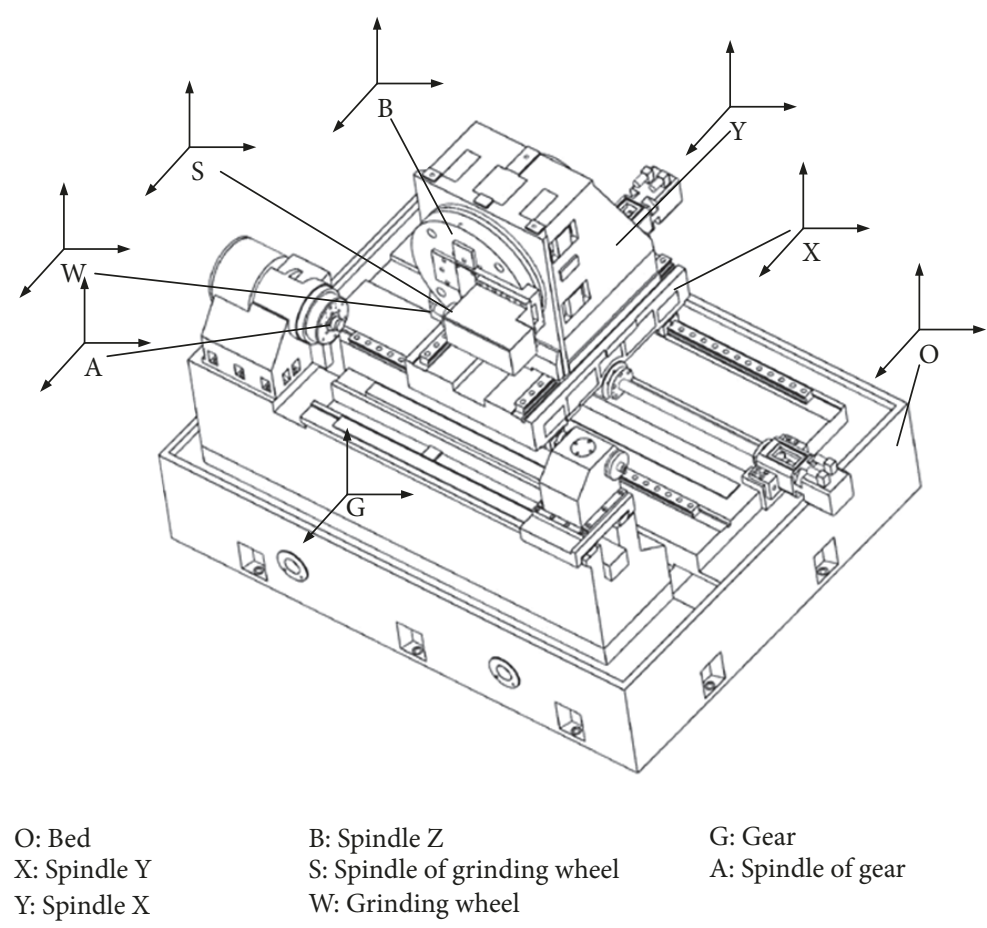

FIgURE 6: The coordinate system of high-precision CNC forming grinding machine setting.

$$
{ }_{B}^{A} T=\left[\begin{array}{cccc}
\cos \varepsilon_{y} \cos \varepsilon_{z} & -\cos \varepsilon_{y} \sin \varepsilon_{z} & \sin \varepsilon_{y} & x \\
\sin \varepsilon_{x} \sin \varepsilon_{y} \cos \varepsilon_{z}+\cos \varepsilon_{x} \sin \varepsilon_{z} & -\sin \varepsilon_{x} \sin \varepsilon_{y} \sin \varepsilon_{z}+\cos \varepsilon_{x} \cos \varepsilon_{z} & -\sin \varepsilon_{x} \cos \varepsilon_{y} & y \\
-\cos \varepsilon_{x} \sin \varepsilon_{y} \cos \varepsilon_{z}+\sin \varepsilon_{x} \sin \varepsilon_{z} & \cos \varepsilon_{x} \sin \varepsilon_{y} \sin \varepsilon_{z}+\sin \varepsilon_{x} \cos \varepsilon_{z} & \cos \varepsilon_{x} \cos \varepsilon_{y} & z \\
0 & 0 & 0 & 1
\end{array}\right]
$$

When the rotation angle $\varepsilon_{x}, \varepsilon_{y}, \varepsilon_{z}$ is very small, there is $\sin \varepsilon_{x} \approx \varepsilon_{x}, \sin \varepsilon_{y} \approx \varepsilon_{y}, \sin \varepsilon_{z} \approx \varepsilon_{z}, \cos \varepsilon_{x} \approx 1$, $\cos \varepsilon_{y} \approx 1, \cos \varepsilon_{z} \approx 1$. When the translation displacement is very small, use $\delta_{x}, \delta_{y}, \delta_{z}$ to separate table $x, y$, and $z$, respectively. Ignoring the second-coordinate transformation matrix is expressed as

$$
{ }_{B}^{A} T=\left[\begin{array}{cccc}
1 & -\varepsilon_{z} & \varepsilon_{y} & \delta_{x} \\
\varepsilon_{z} & 1 & -\varepsilon_{x} & \delta_{y} \\
-\varepsilon_{y} & \varepsilon_{x} & 1 & \delta_{z} \\
0 & 0 & 0 & 1
\end{array}\right]
$$

4.2. Coordinate System Setting. In this paper, the error synthesis model of a high-precision computer numerical control gear grinding machine is discussed by use of homogeneous coordinate transformation method. The model contains geometric error and thermal error, which provides a theoretical basis for carrying out error compensation.

According to the above-described high-precision computer numerical control gear grinding machine basic movement process, we establish a series of coordinate system as shown in Figure 6: machine tool coordinate system O; sliding table coordinate system $\mathrm{X}$; engine base coordinate system $\mathrm{Y}$; wheel frame disk coordinate system B; spindle of grinding wheel coordinate system $S$; grinding wheel coordinate system $\mathrm{W}$; gear spindle coordinate system A; and gear coordinate system $\mathrm{G}$.

For the convenience of calculations, we placed the origin of base coordinates and local coordinates in the zero point $O$, and the same axis direction remains same. The two branches of the coordinate system drive chain are shown in Figure 7.

Branch One. Machine tool, gear spindle, and gear.

Branch Two. Machine tool, slide, machine base, wheel frame disk,, wheel spindle, and wheel.

In the ideal situation, the corresponding positions on the grinding wheel and gear are the same in space. Assume that the coordinate transformation matrix ${ }_{W}^{G} T$ of the gear coordinate system $G$ to the grinding wheel coordinate system $W$ is

$$
{ }_{W}^{G} T=\left({ }_{A}^{G} T \cdot{ }_{O}^{A} T\right) \cdot\left({ }_{X}^{O} T \cdot{ }_{Y}^{X_{Y}} T \cdot{ }_{B}^{Y} T \cdot{ }_{S}^{B} T \cdot{ }_{W}^{S_{W}} T\right)
$$




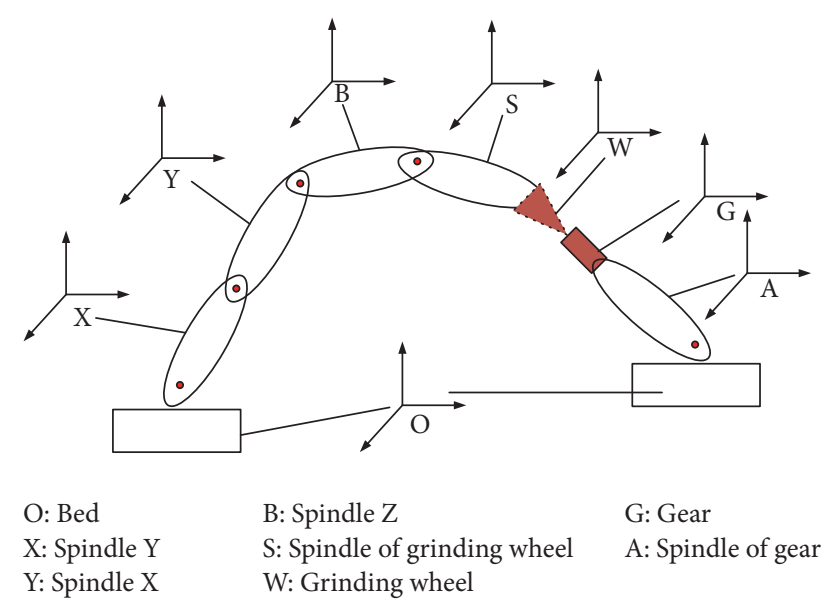

FIGURE 7: The transformation of coordinates system about highprecision $\mathrm{CNC}$ forming grinding machine.

Based on the formation principle of different kinds of errors, the coordinate transformation matrix of the gear coordinate system $G$ to the grinding wheel coordinate system $W$ should be

$$
{ }_{W}^{G} T^{e}=\left({ }_{A}^{G} T^{e} \cdot{ }_{O}^{A} T^{e}\right) \cdot\left({ }_{X}^{O_{X}} T^{e} \cdot{ }_{Y}^{X} T^{e} \cdot{ }_{B}^{Y} T^{e} \cdot{ }_{S}^{B} T^{e} \cdot{ }_{W}^{S_{W}} T^{e}\right)
$$

Erratic movements are indicated by superscripts $e$. In reality, the coordinate transformation matrix of the gear coordinate system $G$ to the grinding wheel coordinate system $W$ is equal to the multiplication of the ideal motion matrix and an error matrix ${ }_{W}^{G} E$, that is,

$$
{ }_{W}^{G} T^{e}={ }_{W}^{G} E \cdot{ }_{W}^{G} T
$$

Based on the premise of small errors, the error motion conversion matrix of the gear coordinate system $G$ to the grinding wheel coordinate system $W$ can be set as

$$
{ }_{W}^{G} E=\left(\begin{array}{cccc}
1 & -\varepsilon_{z} & \varepsilon_{y} & \delta_{x} \\
\varepsilon_{z} & 1 & -\varepsilon_{x} & \delta_{y} \\
-\varepsilon_{y} & \varepsilon_{x} & 1 & \delta_{z} \\
0 & 0 & 0 & 1
\end{array}\right)
$$

$\delta_{x}, \delta_{y}, \delta_{z}$ represent the relative error between the actual machining position of the grinding wheel and the ideal machining position; $\varepsilon_{x}, \varepsilon_{y}, \varepsilon_{z}$ represent the relative error between the actual machining direction of the grinding wheel and the ideal machining direction.

Based on the small error principle, after calculating the theoretical and practical transformation matrices of each sliding pair and the revolute pair, the three matrix equations (12) (14) can be used to get the error motion matrix ${ }_{G}^{W} E$ :

$$
\begin{aligned}
&{ }_{W}^{G} E={ }_{A}^{G} T^{e} \cdot{ }_{O}^{A} T^{e} \cdot{ }_{X} T^{e} \cdot{ }_{Y}^{X} T^{e} \cdot{ }_{B}^{Y} T^{e} \cdot{ }_{S}^{B} T^{e} \cdot{ }_{W}^{S_{W}} T^{e} \\
& \cdot\left({ }_{W}^{S_{W}} T\right)^{-1} \cdot\left({ }_{S}^{B} T\right)^{-1} \cdot\left({ }_{B}^{Y} T\right)^{-1} \cdot\left({ }_{Y}^{X} T\right)^{-1} \cdot\left({ }_{X}^{O_{X}} T\right)^{-1} \\
& \cdot\left({ }_{O}^{A} T\right)^{-1} \cdot\left({ }_{A}^{G} T\right)^{-1}
\end{aligned}
$$

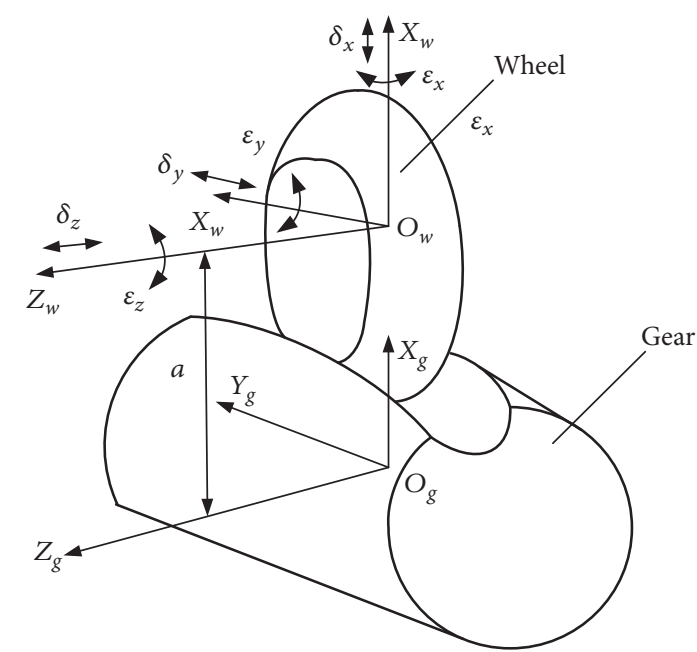

FIGURE 8: Wheel thermal error direction diagram.

${ }_{W}^{S} T$ represents the coordinate conversion matrix of the wheel spindle coordinate system $S$ to the wheel coordinate system $W$. The grinding wheel is installed in the spindle, moving together with the spindle. Therefore, the coordinate transformation matrix between them is unit matrix $I,{ }_{W}^{S} T=I$.

Due to space constraints, there is seldom detailed description for the error solution procedure. Solving the matrix equation by MATLAB and neglecting the highorder infinitesimal small quantities, we finally obtain the comprehensive error model. Wheel angle deviations in three directions are $\varepsilon_{x}, \varepsilon_{y}, \varepsilon_{z}$.Deviations in three directions are $\delta_{x}, \delta_{y}, \delta_{z}$.

4.3. Error Analysis of Gear Forming Grinding. In this paper, the involute spur gear is taken as the research object, through measuring the thermal error, and then studying the thermal error compensation. In general, the error factors that affect the machining accuracy of the gear come from six directions, as shown in Figure 8. The involute spur gear is studied in this paper, so the error in $\mathrm{Y}$ direction has no influence on the gear machining. After dressing grinding wheel, the wheel profile has met the requirements and does not consider the deviation of revolute pair of $\mathrm{Y}$ direction. Because the grinding wheel is revolving and machined around the axis $\mathrm{Z}$, this article does not study the above three errors; the main study is the displacement deviation along the direction $\mathrm{X}$, the rotation deviation of direction $X$, and the displacement deviation of direction $\mathrm{Z}$ on the gear grinding accuracy. The above three errors, respectively, are referred to as radial error, rotating error, and vertical error.

\section{The Impact of Machine Error on the Tooth Profile Accuracy}

While using grinding wheel to grind spur gear with grinding method, the precision of tooth curve is guaranteed by the accuracy of the slide rail and fixture. With many measurements, the accuracy of the tooth curve is very high, reaching 


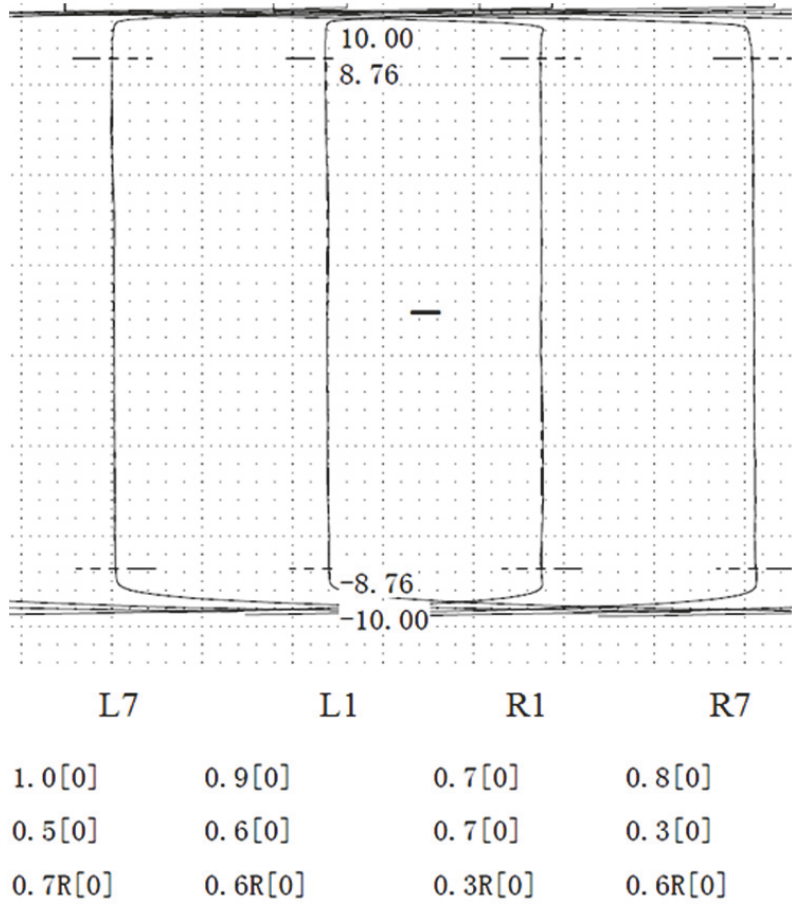

Figure 9: Gear tooth direction measurement results.

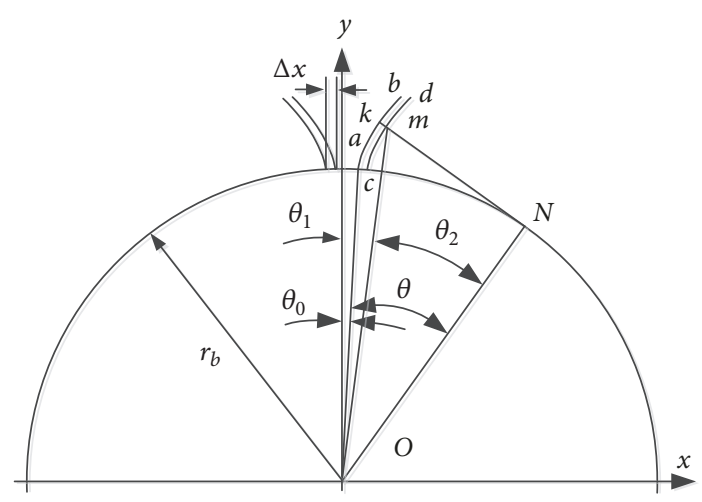

FigurE 10: Error along the $\mathrm{x}$ direction of the wheel (vertical error).

0 or 1 , as shown in Figure 9. Therefore, the main consideration of this manuscript is the influence of thermal error on the accuracy of tooth profile.

The position deviation of grinding wheel refers to the distance of wheel along the axial or vertical direction deviating from the theoretical position, which can be expressed by $\Delta x$ and $\Delta y$. As Figure 10 shows, $\overline{a b}$ is the theoretical involute, $\overline{c d}$ is the actual tooth profile, $r_{b}$ is the radius of rolling circle, $\theta_{0}$ is the theoretical tooth space half-angle, and $\theta$ is the tooth profile rolled angle of the point $k$ on the theoretical tooth profile. According to Figure 10, this article deduces the accurate calculation formula of the tooth profile error caused by the $\Delta x, \Delta y$ in order to accurately analyze the grinding tooth error.

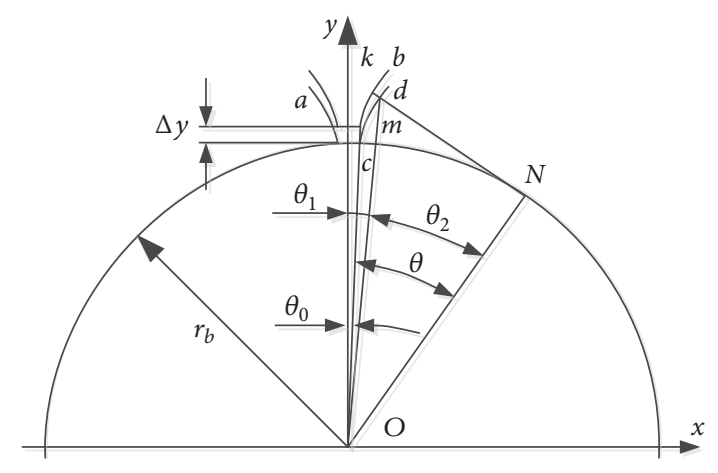

FIGURE 11: Wheel along the y direction deviation of the error (radial error).

Set the equation of theoretical involute of the right tooth profile is

$$
\begin{aligned}
& x=r_{b}\left[\sin \left(\theta+\theta_{0}\right)-\theta \cos \left(\theta+\theta_{0}\right)\right] \\
& y=r_{b}\left[\cos \left(\theta+\theta_{0}\right)+\theta \sin \left(\theta+\theta_{0}\right)\right]
\end{aligned}
$$

When the position deviation of grinding wheel is $\Delta x, \Delta y$, the actual tooth profile after manufacture is

$$
\begin{aligned}
& x_{1}=r_{b}\left[\sin \left(\theta+\theta_{0}\right)-\theta \cos \left(\theta+\theta_{0}\right)\right]+\Delta x \\
& y_{1}=r_{b}\left[\cos \left(\theta+\theta_{0}\right)+\theta \sin \left(\theta+\theta_{0}\right)\right]+\Delta y
\end{aligned}
$$

From any point $M\left(x_{1}, y_{1}\right)$ of the actual tooth profile tangent for the rolling circle, $N$ as the tangent point, the angle between the straight line $O M$ and the axis $y$ is

$$
\theta_{1}=\tan ^{-1} \frac{x_{1}}{y_{1}}
$$

The angle between the line $O M$ and $O N$ is

$$
\theta_{2}=\cos ^{-1}\left(\frac{r_{b}}{\sqrt{x_{1}^{2}+y_{1}^{2}}}\right)
$$

Let the intersection of the straight line $O M$ and the theoretical tooth profile be $k(x, y)$, and it can be seen from Figure 11 that

$$
\theta_{0}+\theta=\theta_{1}+\theta_{2}
$$

Tooth space half-angle $\theta_{0}$ is known, you can get the point $k$ of the tooth profile rolled angle that

$$
\theta=\theta_{1}+\theta_{2}-\theta_{0}
$$

The curvature radius of the point $k$ is

$$
N K=r_{b} \theta
$$

The length of the line segment $N M$ is

$$
N M=\sqrt{x_{1}^{2}+y_{1}^{2}-r_{b}^{2}}
$$


TABLE 2: Gear basic parameters.

\begin{tabular}{lc}
\hline Parameter & Value \\
\hline Number of teeth & 35 \\
Modulus & $2.5 \mathrm{~mm}$ \\
pressure angle & $20^{\circ}$ \\
Tooth width & $20 \mathrm{~mm}$ \\
\hline
\end{tabular}

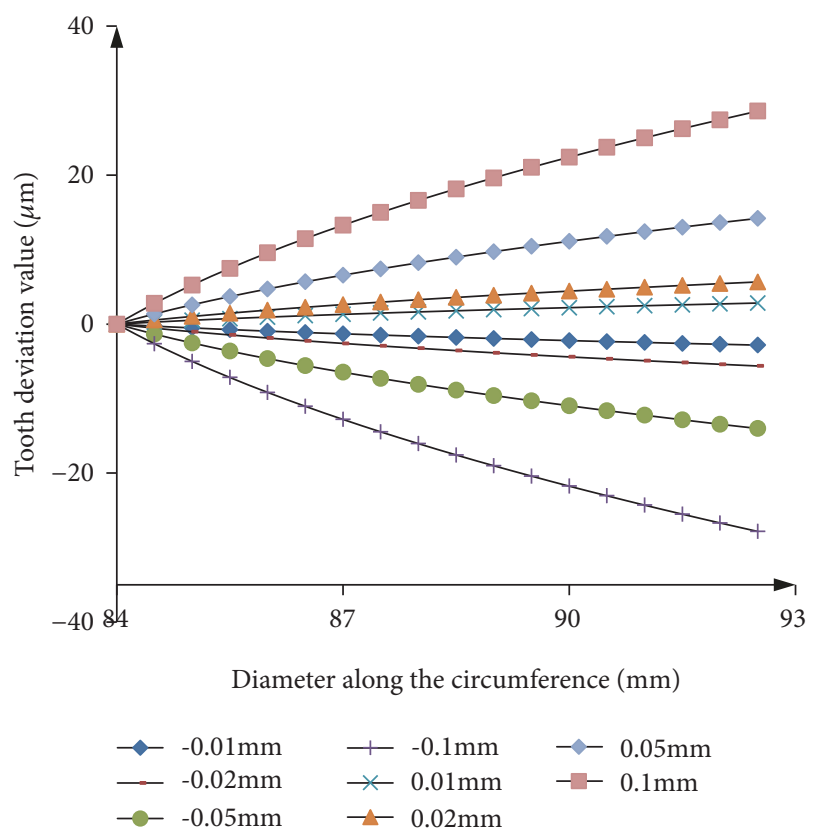

FIGURE 12: Radial error caused by the tooth profile error curve.

We can get the tooth profile error at any point $k(x, y)$ on the theoretical tooth profile, that is,

$$
\begin{aligned}
\Delta J= & N M-N K=\sqrt{x_{1}^{2}+y_{1}^{2}-r_{b}^{2}}-r_{b} \theta \\
= & \sqrt{x_{1}^{2}+y_{1}^{2}-r_{b}^{2}} \\
& -r_{b}\left[\tan ^{-1} \frac{x_{1}}{y_{1}}+\cos ^{-1} \frac{r_{b}}{\sqrt{x_{1}^{2}+y_{1}^{2}}}-\theta_{0}\right]
\end{aligned}
$$

Based on the derivation and discussion of the equation, the tooth profile deviation is deeply studied in this article. The basic parameters of the gears are shown in Table 2 , and the rest are the standard parameters.

Radial error caused by the tooth profile error curve is shown in Figure 12. Vertical error caused by the tooth profile error curve is as shown in Figure 13.

\section{Tooth Profile Error Caused by the Inclination Deviation of the Grinding Wheel}

In the actual design, as shown in Figure 14, the cross section of gear is commonly used to be described by polar coordinates.

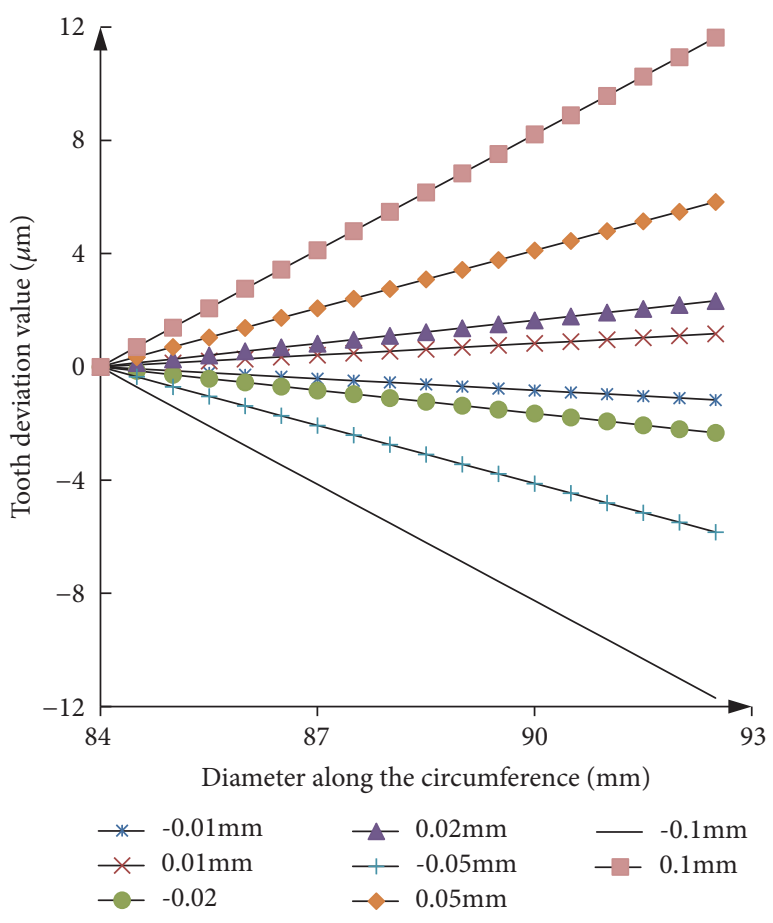

FIGURE 13: Vertical error caused by the tooth profile error curve.
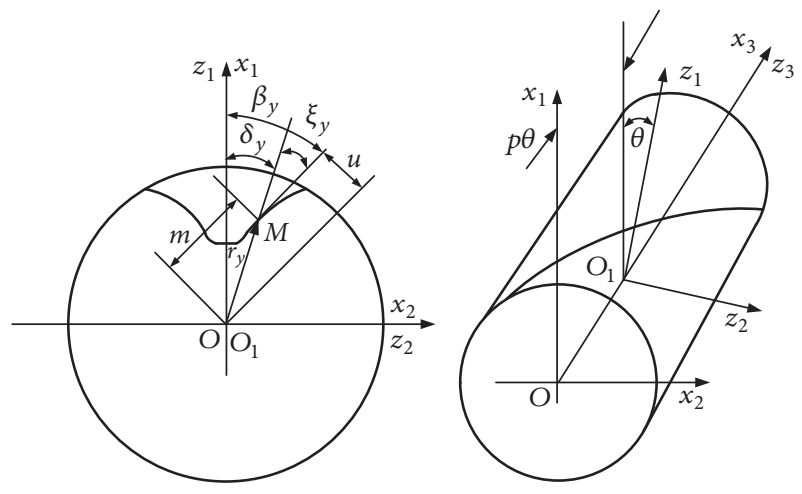

FIgURE 14: The cross section of gear.

When discussing involute spur gear, making the helical angle to 0 that can meet the requirements.

From Figure 14, the polar form of each point on the section of the transverse can be transformed into

$$
\begin{aligned}
& z_{1}(u)=r_{y} \cos \delta_{y} \\
& z_{2}(u)=r_{y} \sin \delta_{y} \\
& z_{3}(u)=0
\end{aligned}
$$

In the formula, $\delta_{y}$ is the polar angle of the point $M$ on the section of the gear transverse; $r_{y}=r_{y}\left(\delta_{y}\right)$ is the vector length of the point $M$ on the section of the gear transverse, which is a function of the polar angle $\delta_{y}$. 
The polar equation of helix surface is

$$
\begin{aligned}
& x=x_{0}(u) \cos \theta-y_{0}(u) \sin \theta \\
& y=x_{0}(u) \sin \theta+y_{0}(u) \cos \theta \\
& z=p \theta
\end{aligned}
$$

$\theta$ represents the rotation angle of the curve around the axis $Z$, and $u$ represents the parameter variable corresponding to the position of each point on the surface. Taking (26) into (27) to get the gear helical equation is

$$
\begin{aligned}
& x_{1}=r_{y} \cos \left(\delta_{y}+\theta\right) \\
& x_{2}=r_{y} \sin \left(\delta_{y}+\theta\right) \\
& x_{2}=p \theta
\end{aligned}
$$

The normal vector on the helical surface of the gear is projected on each axis as

$$
\begin{aligned}
& n_{x 1}=\frac{p \sin \tau}{\cos \xi_{y}} \\
& n_{x 2}=\frac{-p \cos \tau}{\cos \xi_{y}} \\
& n_{x 3}=r_{y}
\end{aligned}
$$

$\xi_{y}$ is the angle between the vector direction of the point $M$ on the section of the gear transverse and the tangent direction of the section of the gear transverse. $\delta_{y}, \xi_{y}$ can be obtained by the following two formulas:

$$
\begin{aligned}
\xi_{y} & =\arctan \left(\frac{r_{y}}{d r_{y} / d \delta_{y}}\right)=\arctan \left(r_{y} \frac{d \delta_{y}}{d r_{y}}\right) \\
\tau & =\delta_{y}+\xi_{y}+\theta
\end{aligned}
$$

The formula for calculating the contact line is

$$
z_{g} n_{x}+a n_{g} \cot \Sigma+\left(a-x_{g}+p \cot \Sigma\right) n_{z}=0
$$

Substituting (28) and (29) into the contact line condition (32), after transformation and simplification, the contact line condition can be obtained as

$$
\frac{n_{2} \cos \tau-n_{1}}{\sin \tau}-\tau-n_{3}=0
$$

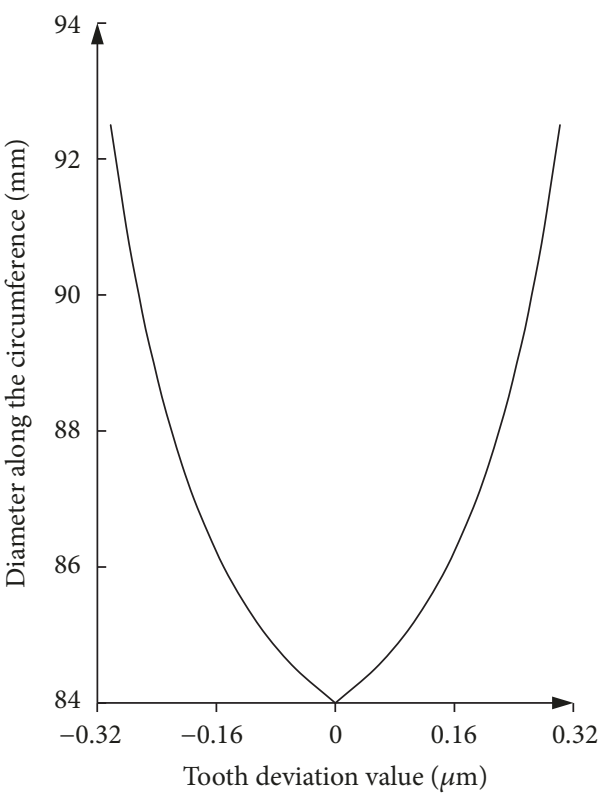

FIGURE 15: The tooth profile error when the wheel deviation is $0.1^{\circ}$.

In the formula,

$$
\begin{aligned}
k_{1} & =a+\frac{p \cot \Sigma}{p^{2}} \\
k_{2} & =\frac{a \cot \Sigma}{p} \\
m & =r_{y} \cos \xi_{y} \\
v & =r_{y} \sin \xi_{y} \\
n_{1} & =k_{1} m \\
n_{2} & =k_{2}+\frac{m^{2}}{p^{2}} \\
n_{3} & =\frac{-m v}{p^{2}}-\delta_{y}-\xi_{y}
\end{aligned}
$$

a represents the center distance of gear.

In order to meet the needs of engineering appliance, the error estimate of solution of matrix equation is less than 0.0001 . According to the above formula, let the spiral angle be 0 ; then the deviation of the grinding wheel can be obtained.

When the wheel deviation is $0.1^{\circ}$, the tooth profile deviation is shown in Figure 15.

The error that occurs when the wheel is deflected from 0 degrees to 1 degree is shown in Figure 16.

\section{Thermal Error Compensation Model for Machine Tool}

The developed model must have the ability to deal with nonlinear problems and the ability to accurately predict thermal errors, which is the key to thermal error compensation. At 


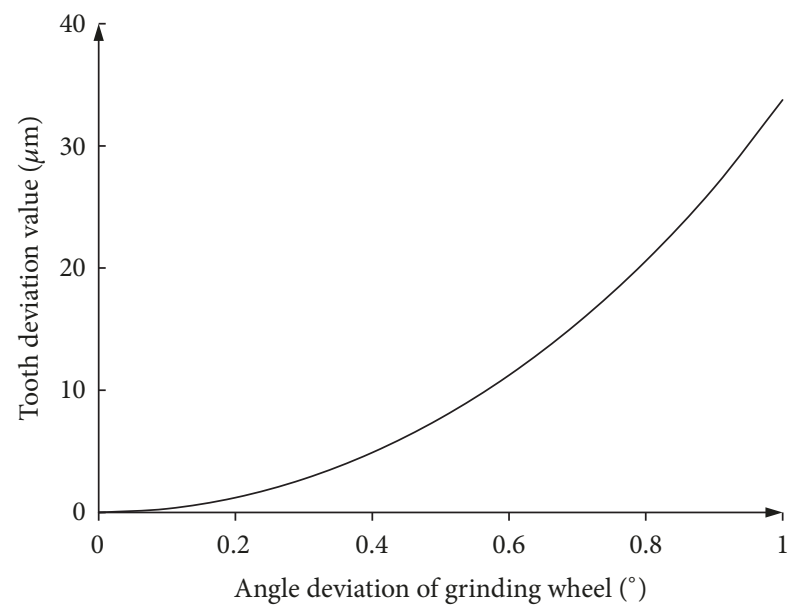

FIGURE 16: The influence of the angle error of the grinding wheel on the tooth profile error.

present, neural networks and grey theory are used to model the thermal error of machine tools.

In this paper, a model based on partial least squares neural network is presented, which takes full advantage of partial least squares regression in solving the multiple linear problem. At the same time, this method is improved by importing the neural network algorithm, the parameters of partial least squares regression are trained by this learning algorithm, which makes the new model have the ability of dealing with nonlinear problems.

\subsection{Partial Least Squares Neural Network Modeling Method.} Partial least squares regression (PLSR) was first presented by Wold to deal with the multiple linear problem of variables in data analysis. This approach is a bit similar to principal component analysis (PCA), but the advantage of PLSR is that both independent variable and dependent variables are used in the process, not just for independent variables. The specific theory of partial least squares regression can refer to literature [19-28].

Partial least squares regression, although it can deal with the problem of multiple linear between independent variables, is a linear algorithm. For the nonlinearity of machine tool thermal error, this method needs to be improved. We introduce the learning rules of neural network to establish the algorithm of partial least squares neural network.

The structure of partial least squares neural network can be shown in Figure 17; different stages of calculation correspond to different PLS factors $h$ and are determined by the optimal number of factors $h^{\circ}$.

By Partial Least Squares Neural Network (PLSNN) method, the Hebbian learning plan in neural networks is used to calculate $\widehat{w}_{h}, \widehat{v}_{h}$, and $\widehat{b}_{h}$. The error function and learning algorithm are as follows:

$$
\begin{aligned}
e^{w}{ }_{a i} & =a_{i}-c_{i} w_{h} \\
e^{b}{ }_{a i} & =a_{i}-\widehat{t}_{h i} w_{h} \\
e^{v}{ }_{c i} & =c_{i}-v_{h} \widehat{t}_{h i}
\end{aligned}
$$

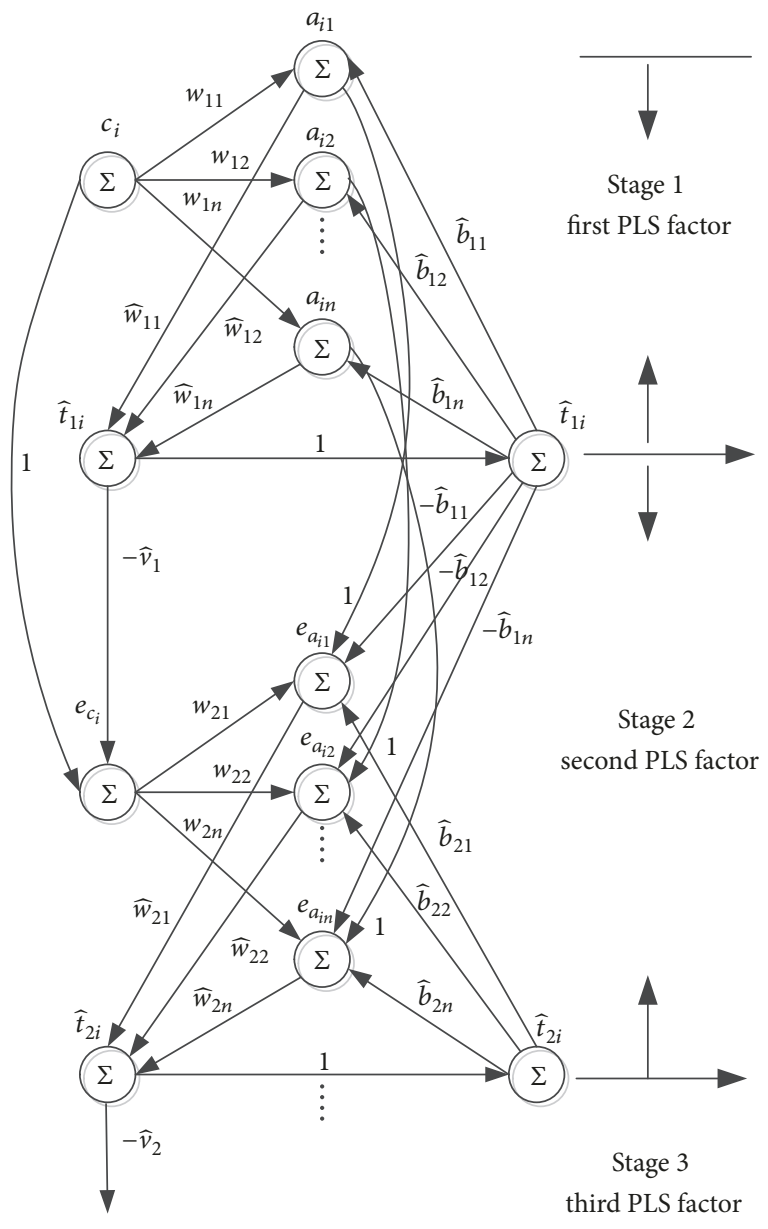

FIGURE 17: Partial least squares neural network structure.

$$
\begin{aligned}
\widehat{w}_{h}(k+1) & =\widehat{w}_{h}(k)+\mu_{w} S_{w} c_{i} g\left[a_{i}-c_{i} \widehat{w}_{h}(k)\right] \\
\widehat{b}_{h}(k+1) & =\widehat{b}_{h}(k)+\mu_{b} S_{b} \widehat{t}_{h i} g\left[a_{i}-\widehat{t}_{h i} \widehat{b}_{h}(k)\right] \\
\widehat{v}_{h}(k+1) & =\widehat{v}_{h}(k)+\mu_{v} S_{v} \widehat{t}_{h i} g\left[a_{i}-\widehat{t}_{h i} \widehat{v}_{h}(k)\right]
\end{aligned}
$$

Among them, coefficient of learning rate $\mu_{w}, \mu_{b}, \mu_{v}$ satisfies $0<\mu_{w}<\left(\sum_{i=1}^{m} c_{i}^{2}\right)^{-1}$ and $\mu_{w} \geq \mu_{b} \geq \mu_{v} . S_{w}, S_{b}$ is positive symmetric weight matrix, $S_{y}$ is positive rational number, and $g(\bullet)$ is derivative of Nonlinear Weight Function.

\section{Experimental Results}

From this we know that we can judge the tooth surface accuracy by measuring the gear. The gear is grinded and measured under different ambient temperatures, and the thermal error of the machine could be obtained indirectly. At a certain temperature, the tooth profile deviation of the gear is shown in Figure 18.

In this paper, the temperature distribution of machine tool is measured by a noncontact thermal infrared imager. When the machine tool is on a working state, the grinding test of gear every $2^{\circ} \mathrm{C}$, according to the change of the ambient temperature and the precision of the tooth profile, is measured. The method of partial least squares neural 


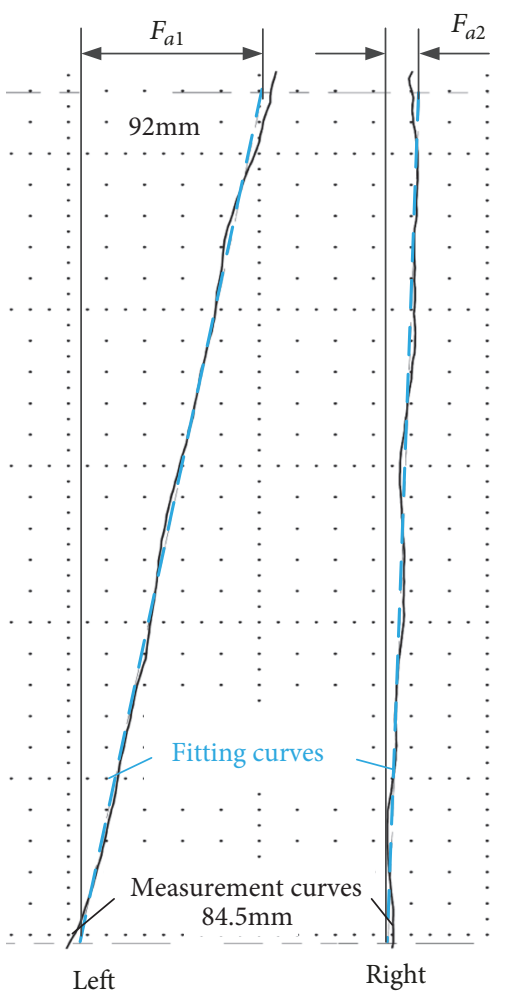

Figure 18: Profile deviation.

network was used to model the errors in three directions. The measured and fitted values of the radial error are shown in Figure 19. The maximum residual error can be calculated as $0.51 \mu \mathrm{m}$ from the residual curve in the figure. The measured and fitted values of the vertical error are shown in Figure 20. The residual error curve in the figure shows the maximum residual error of $0.42 \mu \mathrm{m}$. The measured value and the fitted value of the angular error caused by the angular deviation are shown in Figure 21. The residual error curve in the figure shows the maximum residual error is $0.48 \mu \mathrm{m}$, and the model has good fitting ability to the thermal error data used in modeling.

Although the model of partial least squares neural network has good predictive ability for modeling data, the ability of predicting thermal error is the key which can be applied in thermal error compensation. Therefore, in order to verify the prediction ability of the model for thermal error, a set of thermal error data was measured and used as validation data of thermal error data. As space is limited, only the validation data for radial deviations is shown in Figure 22.

It can be obtained from the diagram that the maximum value of the predicted residual is $0.85 \mu \mathrm{m}$, and the model has good prediction ability for the thermal error of the machine tool. According to the experimental results and fitting curve data, the thermal error of machine tools is compensated for different ambient temperature. After compensation, the gear grinding results are shown in Figure 23, and the accuracy level of gear teeth reaches 4 .

In order to make further study on the performance of the model, taking the radial deviation as the comparison object,

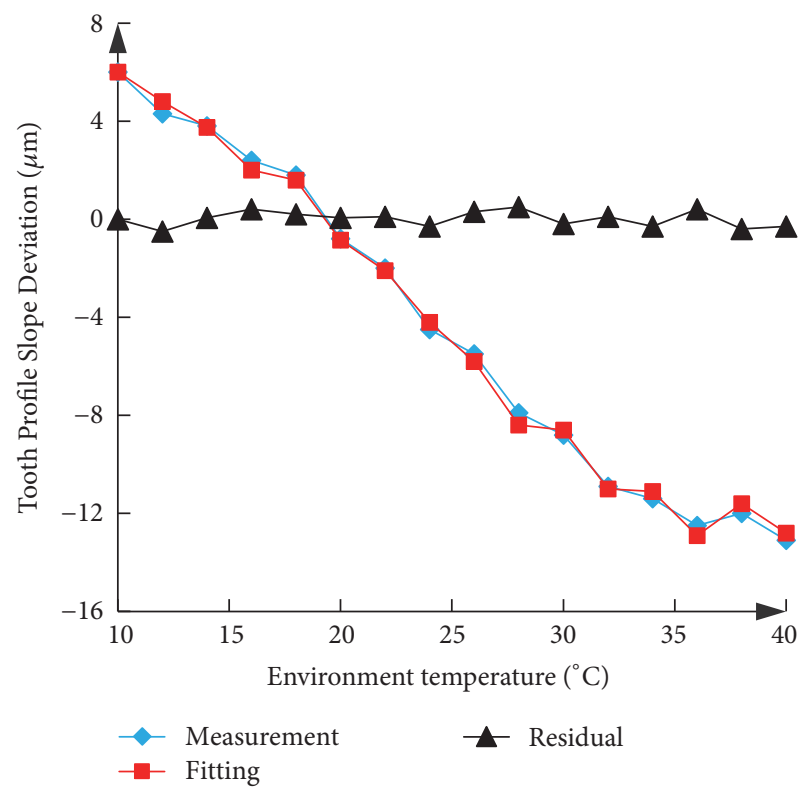

FIgURE 19: Thermal error (radial deviation) of measurement and model fitting.

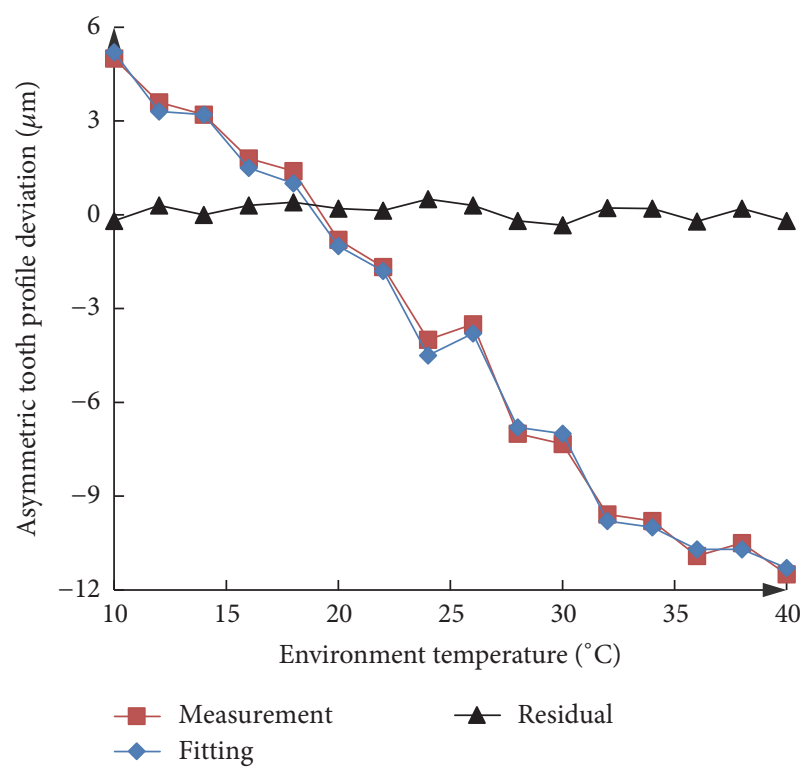

FIGURE 20: Thermal error (vertical deviation) of measurement and model fitting.

and using other common methods to model and predict thermal error. The three models are partial least squares regression model (PLSRM), multiple regression model (MRM), and neural network model (NNM), and the performance of each model is compared as shown in Table 3.

The partial least squares neural network modeling method presented in this paper is superior to the commonly used method in fitting ability, and it also has good prediction accuracy and robustness, which is shown in Table 3. 


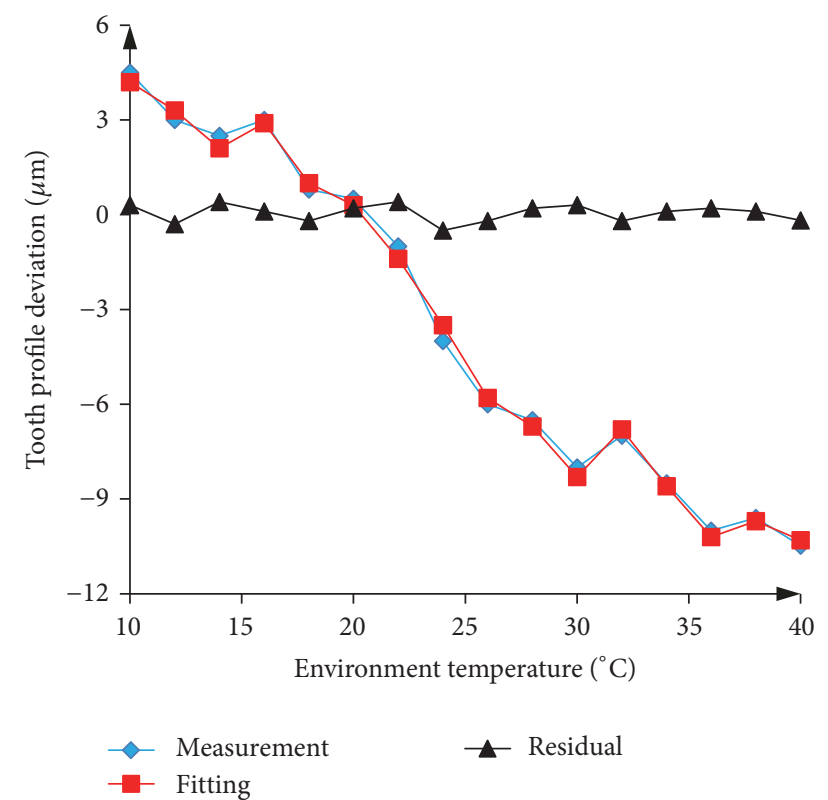

FIGURE 21: Thermal error of measurement and model fitting (rotating error).

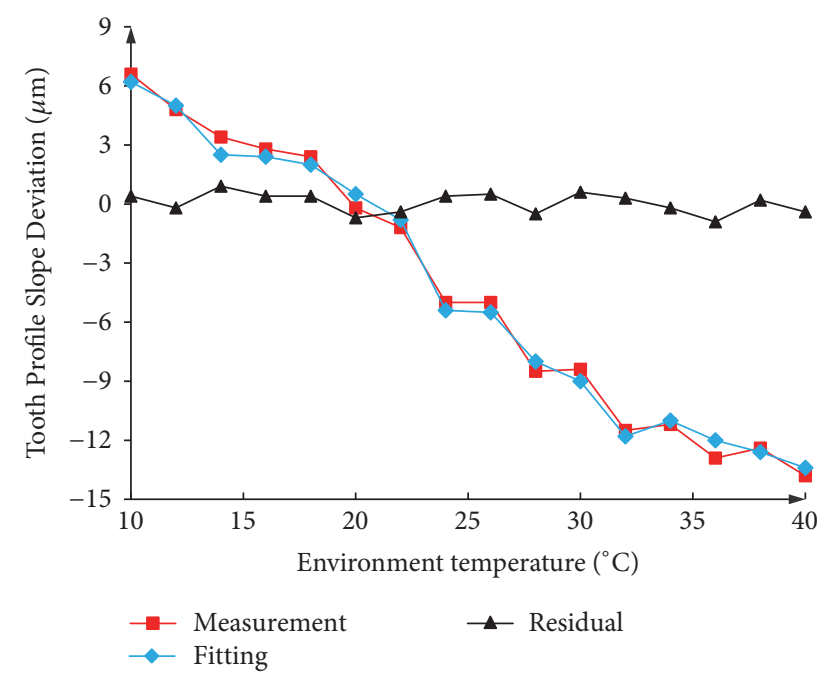

FIGURE 22: Model error prediction capability verification (radial error).

TABLE 3: The performance comparison of different models.

\begin{tabular}{lcc}
\hline Model & Modeling $1(\mu \mathrm{m})$ & Modeling $2(\mu \mathrm{m})$ \\
\hline PLSRM & 0.91 & 1.42 \\
MRM & 0.56 & 1.68 \\
NNM & 0.74 & 1.13 \\
PLSNN & 0.51 & 0.85 \\
\hline
\end{tabular}

\section{Conclusions}

In this paper, the thermal error of the high-precision CNC forming grinding machine was tested. The thermal error of the machine tool was analyzed by the formation of tooth

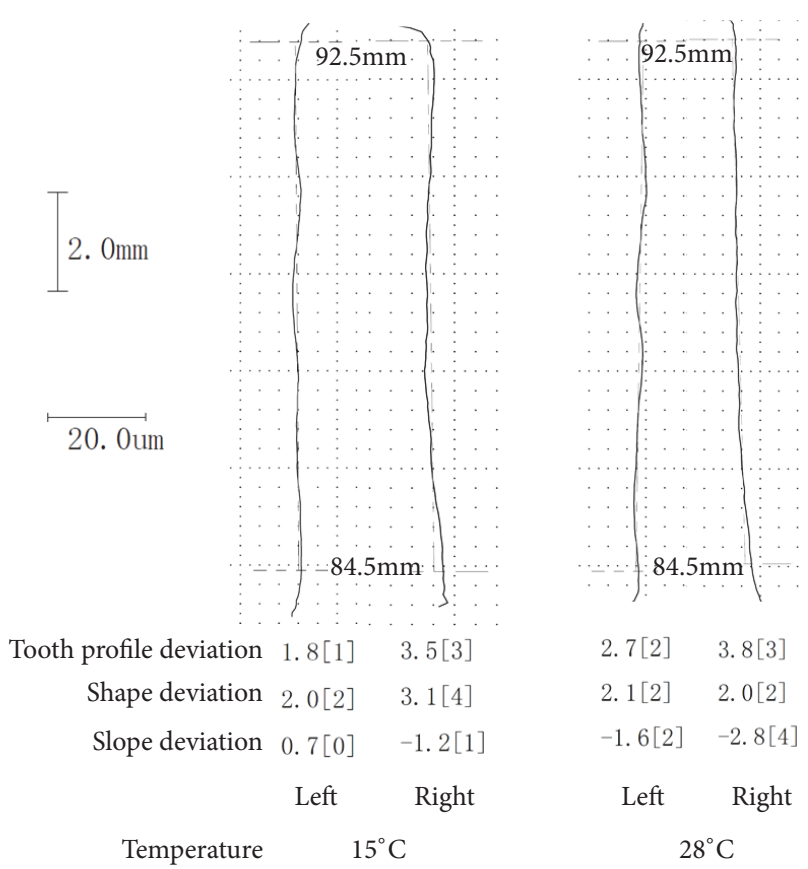

FIGURE 23: Compensation gear measurement results.

profile deviation. The partial least squares neural network method was presented to model and predict the thermal error. Field test data show that, at different ambient temperatures, after thermal error compensation, the accuracy of the gear can reach four levels. To solve the problem of thermal error modeling and prediction in high-precision $\mathrm{CNC}$ forming grinding machine, we can reach the following conclusions.

(1)By measuring the thermal error indirectly, the thermal error of the machine tool under load can be measured. A simple mathematical model can achieve high prediction accuracy.

(2) In this paper, the relationship between the machine tool thermal error and the ambient temperature is studied by taking the ambient temperature as a variable. This method provides a new method and train of thought for the thermal error compensation of the machine tool and provides reference for the factory production.

(3) After compensating by this method, the precision of the gears processed under different ambient temperatures reaches four levels, which provides a new method for highprecision gear grinding.

\section{Data Availability}

The data used to support the findings of this study are available from the corresponding author upon request.

\section{Conflicts of Interest}

The authors declare that there are no conflicts of interest regarding the publication of this paper. 


\section{Acknowledgments}

The authors would like to thank Shanghai Science and Technology Commission (Science and Technology Support Program for the People's Livelihood), the process adaptability test, evaluation, and application on NC equipment manufacturing for aerospace complex structural parts, Grant no. 15110502300 .

\section{References}

[1] X. Sitong, Jianguo Y., and Z. Yi, "Modeling method for splindle thermal error based on mechanism analysis and thermal basic characteristics tests," Journal of Mechanical Engineering, vol. 50, no. 11, pp. 144-152, 2014.

[2] H. Cao, L. Zhu, X. Li, P. Chen, and Y. Chen, "Thermal error compensation of dry hobbing machine tool considering workpiece thermal deformation," The International Journal of Advanced Manufacturing Technology, vol. 86, no. 5-8, pp. 17391751, 2016.

[3] J. Vyroubal, "Compensation of machine tool thermal deformation in spindle axis direction based on decomposition method," Precision Engineering, vol. 36, no. 1, pp. 121-127, 2012.

[4] G. Li, Z. Wang, W. Zhu, and A. Kubo, "A function-oriented active form-grinding method for cylindrical gears based on error sensitivity," The International Journal of Advanced Manufacturing Technology, vol. 92, no. 5-8, pp. 3019-3031, 2017.

[5] W. Ding, H. Li, L. Zhang, J. Xu, Y. Fu, and H. Su, "Diamond wheel dressing: A comprehensive review," Journal of Manufacturing Science and Engineering, vol. 139, no. 12, 2017.

[6] W. Ding, C. Dai, T. Yu, J. Xu, and Y. Fu, "Grinding performance of textured monolayer CBN wheels: Undeformed chip thickness nonuniformity modeling and ground surface topography prediction," The International Journal of Machine Tools and Manufacture, vol. 122, pp. 66-80, 2017.

[7] C. Dai, W. Ding, J. Xu, Y. Fu, and T. Yu, "Influence of grain wear on material removal behavior during grinding nickelbased superalloy with a single diamond grain," The International Journal of Machine Tools and Manufacture, vol. 113, pp. 49-58, 2017.

[8] C. Liu, W. Ding, T. Yu, and C. Yang, "Materials removal mechanism in high-speed grinding of particulate reinforced titanium matrix composites," Precision Engineering, vol. 51, pp. 68-77, 2018.

[9] W. Ding, B. Linke, Y. Zhu et al., "Review on monolayer CBN superabrasive wheels for grinding metallic materials," Chinese Journal of Aeronautics, vol. 30, no. 1, pp. 109-134, 2017.

[10] R. Takeda, S. Fang, Y. Liu, and M. Komori, "Precision compensation method for tooth flank measurement error of hypoid gear," Measurement, vol. 89, pp. 305-311, 2016.

[11] C. FJ, Y. SH, and H. H, "Profile error compensation in ultraprecision grinding of aspheric surfaces with on-machine measurement," vol. 50, pp. 480-486, 2010.

[12] Z. Hu, Z. Yunfei, and T. Xiaoqi, "Motion Error Identification and Compensation of CNC Machine Tools Based on Laser Interferometer," Chinese Journal of Mechanical Engineering, vol. 13, no. 21, pp. 1838-1841, 2002.

[13] H. F. F. Castro and M. Burdekin, "Evaluation of the measurement uncertainty of a positional error calibrator based on a laser interferometer," The International Journal of Machine Tools and Manufacture, vol. 45, no. 3, pp. 285-291, 2005.
[14] G. Zhang, R. Ouyang, B. Lu, R. Hocken, R. Veale, and A. Donmez, "A Displacement Method for Machine Geometry Calibration," CIRP Annals - Manufacturing Technology, vol. 37, no. 1, pp. 515-518, 1988.

[15] G. Chen, J. Yuan, and J. Ni, "Displacement measurement approach for machine geometric error assessment," The International Journal of Machine Tools and Manufacture, vol. 41, no. 1, pp. 149-161, 2001.

[16] F. Jinwei, T. Yue, and S. Guorong, "Technology of NC Machine Error Parameter Identification Based on Fourteen Displacement Measurement Line," Journal of Beijing University of Technology, vol. 26, no. 2, pp. 11-15, 2000.

[17] L. Youwu, L. Libing, and Z. Xiaosong, "Research on Error Compensation Technology of CNC Machine Tool," Chinese Journal of Mechanical Engineering, vol. 9, no. 12, pp. 48-52, 1998.

[18] E. Miao, Y. Gong, P. Niu, C. Ji, and H. Chen, "Robustness of thermal error compensation modeling models of CNC machine tools," The International Journal of Advanced Manufacturing Technology, vol. 69, no. 9-12, pp. 2593-2603, 2013.

[19] S. JinHua, Key Technique and Application in Error Compensation for CNC Machine Tools, Shanghai Jiao Tong University, 2008.

[20] Y. Shen, X. Liu, D. Li, and Z. Li, "A method for grinding face gear of double crowned tooth geometry on a multi-axis CNC machine," Mechanism and Machine Theory, vol. 121, pp. 13391351, 2018.

[21] H. Yang and J. Ni, "Dynamic modeling for machine tool thermal error compensation," Journal of Manufacturing Science and Engineering, vol. 125, no. 2, p. 245, 2003.

[22] Y. Zhang, J. Yang, and H. Jiang, "Machine tool thermal error modeling and prediction by grey neural network," The International Journal of Advanced Manufacturing Technology, vol. 59, no. 9-12, pp. 1065-1072, 2012.

[23] W. LIN, "Modeling of NC Machine Tool Thermal Error Based on Adaptive Best-fitting WLS-SVM," Journal of Mechanical Engineering, vol. 45, no. 03, p. 178, 2009.

[24] Y. Li, W. Zhao, S. Lan, J. Ni, W. Wu, and B. Lu, "A review on spindle thermal error compensation in machine tools," The International Journal of Machine Tools and Manufacture, vol. 95, pp. 20-38, 2015.

[25] R. Tan, B. Chen, C. Peng, and X. Li, "Study on spatial curve meshing and its application for logarithmic spiral bevel gears," Mechanism and Machine Theory, vol. 86, pp. 172-190, 2015.

[26] S. Berbinschi, V. Teodor, and N. Oancea, "3D graphical method for profiling gear hob tools," The International Journal of Advanced Manufacturing Technology, vol. 64, no. 1-4, pp. 291304, 2013.

[27] W. Guo, S. Mao, Y. Yang, and Y. Kuang, "Optimization of cutter blade profile for face-hobbed spiral bevel gears," The International Journal of Advanced Manufacturing Technology, vol. 85, no. 1-4, pp. 209-216, 2016.

[28] W. Zhonghou, Simulation of hypoid gears dynamic performance, Science Press, Beijing, China, 2013. 


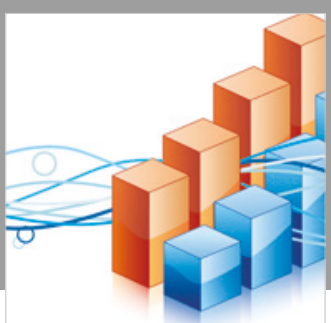

Advances in

Operations Research

\section{-n-m}
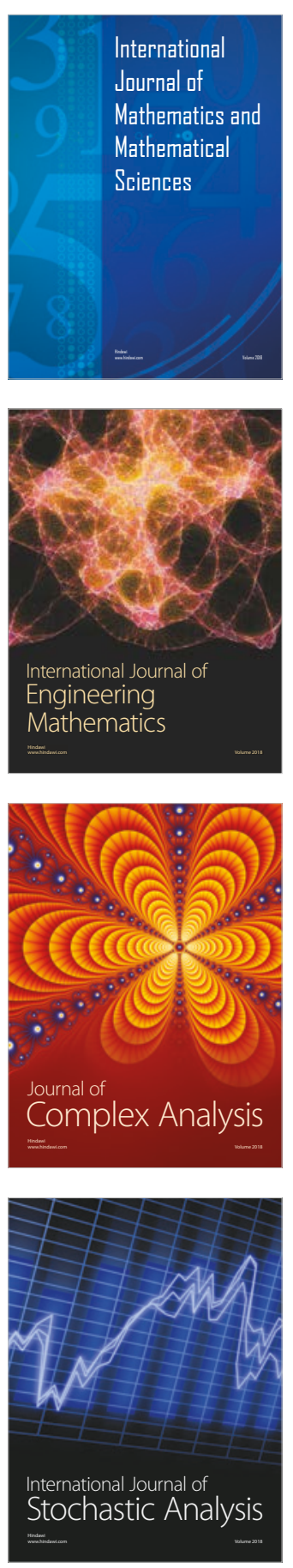
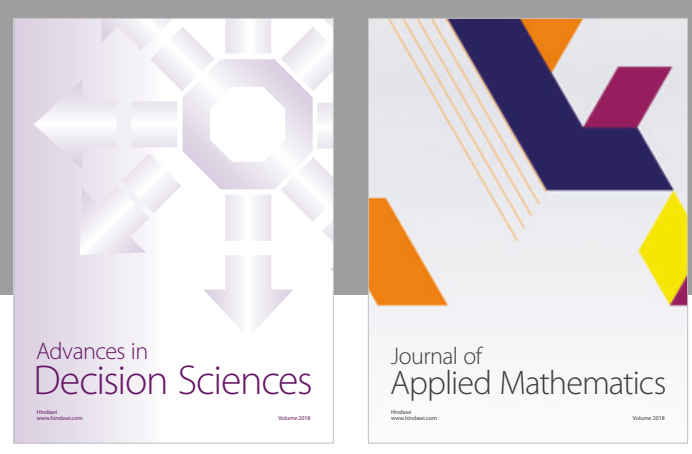

Journal of

Applied Mathematics
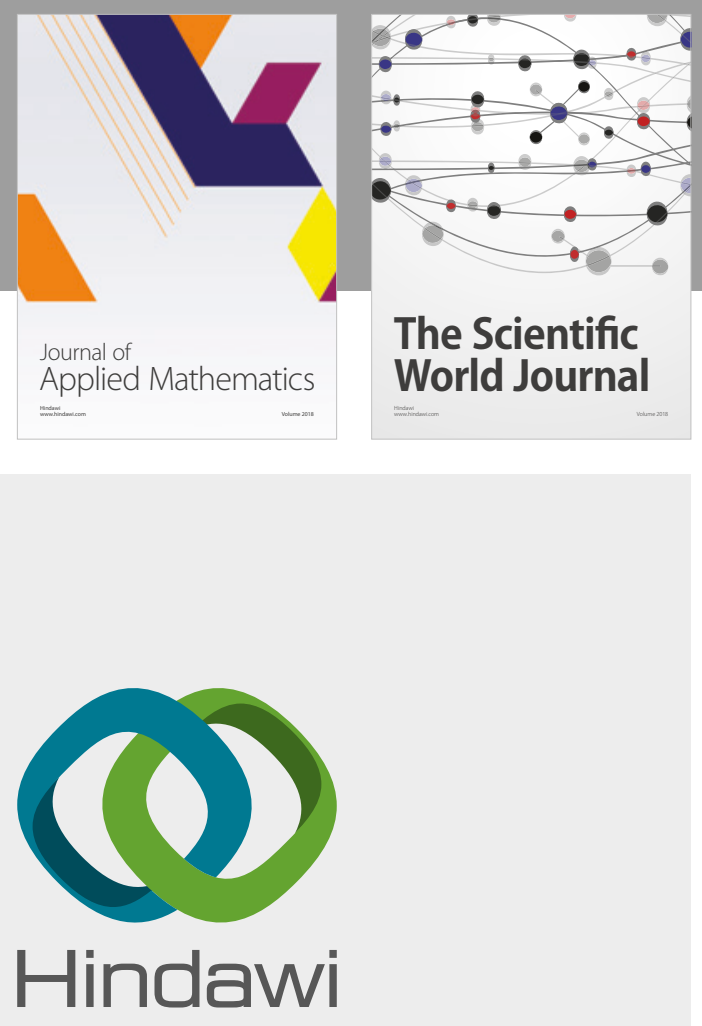

Submit your manuscripts at

www.hindawi.com

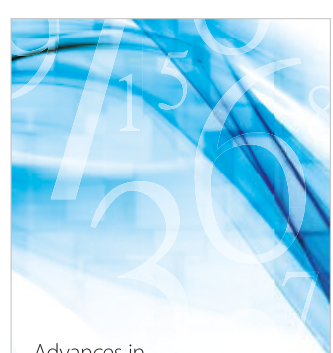

Advances in
Numerical Analysis
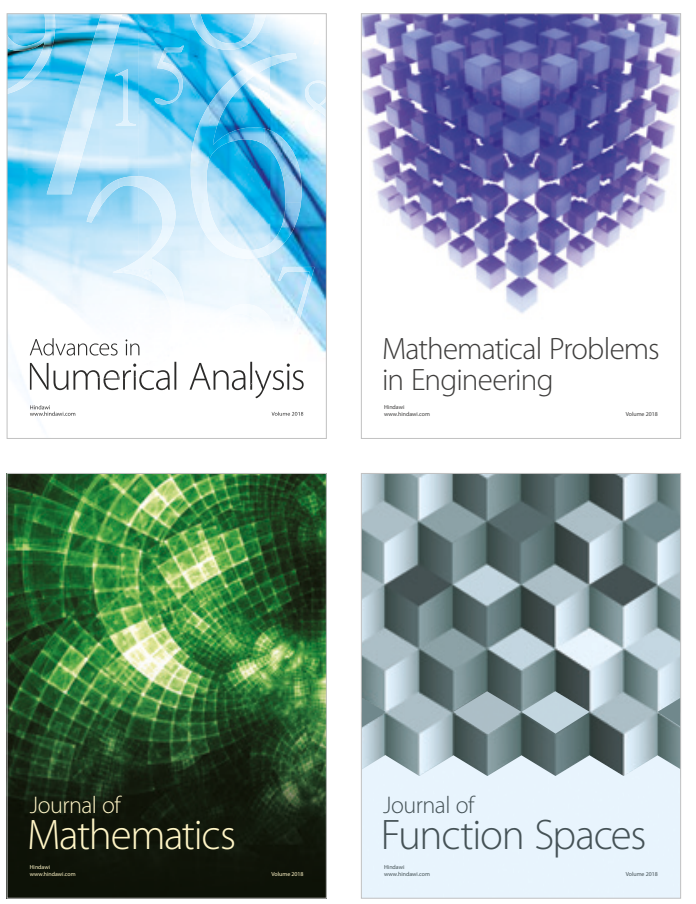

Mathematical Problems in Engineering

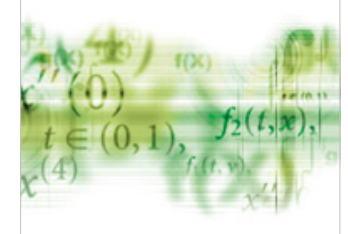

International Journal of

Differential Equations

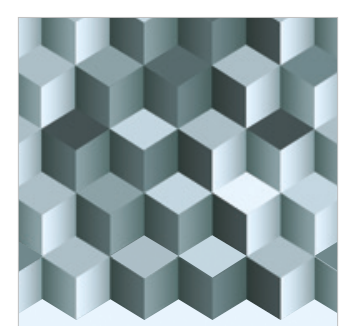

Journal of

Function Spaces

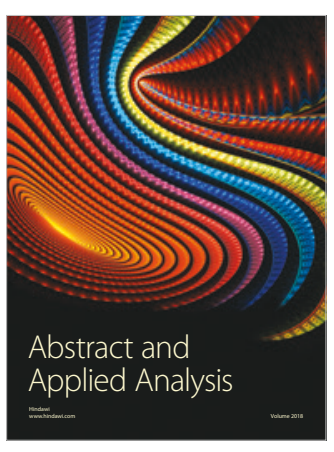

The Scientific

World Journal

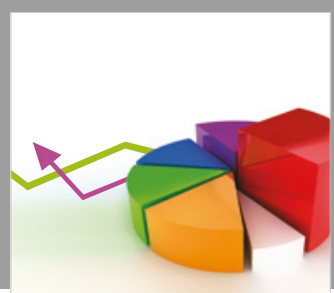

Journal of

Probability and Statistics
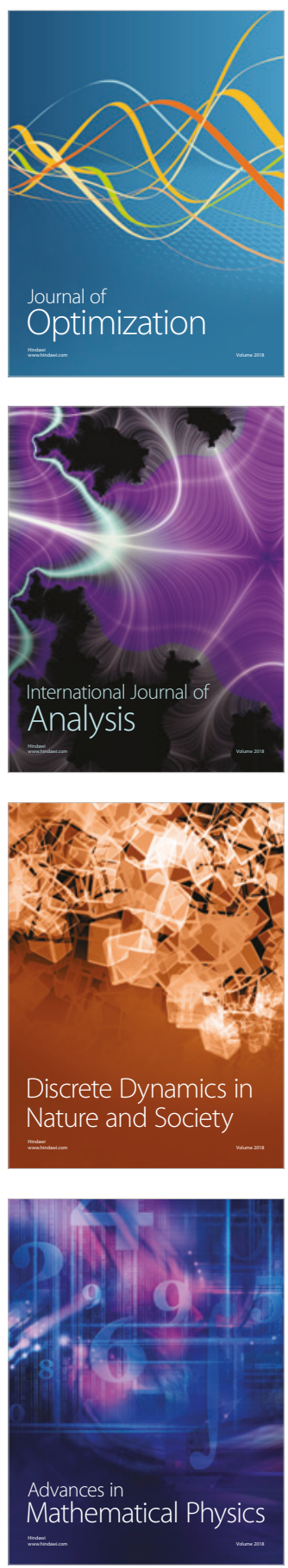